\title{
Repeat pneumococcal polysaccharide vaccine in Indigenous Australian adults is associated with decreased immune responsiveness
}

\author{
Sarah Moberley ${ }^{\mathrm{a}, 1}$, Paul V. Licciardi ${ }^{\mathrm{b}, \mathrm{g}, 1}$, Anne Balloch ${ }^{\mathrm{b}}$, Ross Andrews ${ }^{\mathrm{a}, *}$, Amanda J. Leach ${ }^{\mathrm{a}}$, \\ Marie Kirkwood $^{\text {a }}$, Paula Binks ${ }^{a}$, Kim Mulholland ${ }^{\text {b,c }}$, Jonathan Carapetis ${ }^{d}$, Mimi L.K. Tang ${ }^{\text {e,f,g }}$, Sue Skull ${ }^{\text {h,i }}$ \\ ${ }^{a}$ Menzies School of Health Research, Child Health Division, Charles Darwin University, Northern Territory, Australia \\ ${ }^{\mathrm{b}}$ Pneumococcal Research Group, Murdoch Childrens Research Institute, Royal Children's Hospital, Victoria, Australia \\ ${ }^{\mathrm{c}}$ London School of Hygiene and Tropical Medicine, London, United Kingdom \\ ${ }^{\mathrm{d}}$ Telethon Kids Institute, University of Western Australia, Perth, Australia \\ e Department of Allergy and Immunology, Royal Children's Hospital, Victoria, Australia \\ ${ }^{\mathrm{f}}$ Allergy and Immune Disorders Group, Murdoch Childrens Research Institute, Victoria, Australia \\ ${ }^{\mathrm{g}}$ Department of Paediatrics, University of Melbourne, Victoria, Australia \\ ${ }^{\mathrm{h}}$ School of Paediatrics and Child Health, University of Western Australia, Perth, Australia \\ ${ }^{\mathrm{i}}$ Department of Clinical Research, Princess Margaret Hospital for Children, Perth, Australia
}

\section{A R T I C L E I N F O}

\section{Article history:}

Received 6 October 2016

Received in revised form 8 April 2017

Accepted 13 April 2017

Available online 25 April 2017

\section{Keywords:}

Pneumococcal polysaccharide vaccine

Immunogenicity

Hyporesponsiveness

Adequate immune response

Indigenous

\begin{abstract}
A B S T R A C T
Background: Indigenous adults residing in the Northern Territory of Australia experience elevated rates of invasive pneumococcal disease despite the routine use of 23-valent pneumococcal polysaccharide vaccine $(23 \mathrm{vPPV})$. We hypothesised that the limited protection from $23 \mathrm{vPPV}$ may be due to hyporesponsiveness as a result of vaccine failure from repeated vaccination. To explore this possibility, we evaluated the immune response to a first and second dose of 23vPPV in Indigenous adults and a first dose of $23 \mathrm{vPPV}$ in non-Indigenous adults.

Methods: Serotype-specific IgG was measured by ELISA for all 23 vaccine serotypes at baseline and at one month post-vaccination. Individuals were considered to have an adequate immune response if paired sera demonstrated either: a four-fold rise in antibody concentration; a two-fold rise if the post vaccination antibody was $>1.3 \mu \mathrm{g} / \mathrm{ml}$ but $<4.0 \mu \mathrm{g} / \mathrm{ml}$; or a post-vaccination antibody concentration $>4.0 \mu \mathrm{g} / \mathrm{ml}$ for at least half of the serotypes tested (12/23). Our per-protocol analysis included the comparison of outcomes for three groups: Indigenous adults receiving a second 23vPPV dose $(\mathrm{N}=20)$ and Indigenous $(\mathrm{N}=60)$ and non-Indigenous adults $(\mathrm{N}=25)$ receiving their first 23vPPV dose.

Results: All non-Indigenous adults receiving a first dose of $23 \mathrm{vPPV}$ mounted an adequate immune response (25/25). There was no significant difference in the proportion of individuals with an adequate response using our definition (primary endpoint), with $88 \%$ of Indigenous adults mounted an adequate response following first dose $23 \mathrm{vPPV}$ (53/60) compared to $70 \%$ having an adequate response following a second dose of $23 \mathrm{vPPV}(14 / 20 ; \mathrm{p}=0.05)$. The risk difference between Indigenous participants receiving first dose compared to non-Indigenous participants receiving first dose was significant when comparing a response threshold of at least $70 \%(-27 \%, 95 \% \mathrm{CI}:-43 \%$ to $-11 \% ; \mathrm{p}=0.01)$ and $90 \%(-38 \%, 95 \% \mathrm{CI}$ : $-60 \%$ to $-16 \%$; $\mathrm{p}=0.006$ ) of serotypes with a positive response.

Conclusion: Indigenous participants demonstrated a poorer response to a first dose 23vPPV compared to their non-Indigenous counterparts, with lower IgG following a second 23vPPV dose. These findings highlight the critical need to evaluate the efficacy of future pneumococcal vaccine programs in the Australian Indigenous populations that recommend repeated doses of 23vPPV.
\end{abstract}

(C) 2017 The Authors. Published by Elsevier Ltd. This is an open access article under the CC BY-NC-ND license (http://creativecommons.org/licenses/by-nc-nd/4.0/).

\footnotetext{
* Corresponding author at: Menzies School of Health Research, Australia.

E-mail address: ross.andrews@menzies.edu.au (R. Andrews).

1 These authors contributed equally to this manuscript.
}

\section{Introduction}

Indigenous adults in the Northern Territory of Australia suffer one of the highest reported rates of pneumococcal disease worldwide, exceeding 10-fold higher than non-Indigenous adults [1]. A 
unique schedule of repeated vaccination with the 23-valent pneumococcal polysaccharide vaccine (23vPPV) is recommended for Indigenous adults residing in the Northern Territory (NT) of Australia owing to their elevated rates of pneumococcal disease $[2,3]$. Since 1995, 23vPPV has been recommended for all Indigenous Australian adults aged 50 years and over and for all Australians aged $15-49$ years with medical risk factors. As a regional initiative in 2000, this was expanded to include all Indigenous adults in the NT aged 15 years and over [4]. Non-Indigenous adults without medical risk factors receive their first dose at 65 years of age. Revaccination was initially recommended every five years, but since 2003, a maximum of three lifetime doses has been recommended for Indigenous adolescents and adults and nonIndigenous adults with medical risk factors: a second dose five years after the first dose and then a third dose ten years after the second, or at age 50 years, whichever is later [5].

This unique 23vPPV regimen has not been associated with a reduction in invasive pneumococcal disease (IPD) incidence within Indigenous adults residing in the NT, although vaccination coverage has been generally low [1]. While there is some evidence of an adequate immunological response to revaccination, no data are available from randomised controlled trials determining clinical efficacy [6-9]. Immune hyporesponsiveness, associated with the production of attenuated serotype-specific IgG responses to vaccine serotypes, has been suggested to result following repeated polysaccharide immunisation and has been demonstrated following 23vPPV in Fijian children [10], although this was no longer apparent by 5 years of age [11]. To investigate the possibility that hyporesponsiveness following repeat vaccination may be one factor contributing to persistently high rates of pneumococcal disease in Indigenous adults, we compared the immune response following a second dose of 23vPPV in Indigenous Australians with the response following a first dose in both Indigenous and nonIndigenous Australians.

\section{Ethical approval}

The study was approved by the Human Research Ethics Committee of the NT Department of Health and the Menzies School of Health Research (06/57), and includes assessment by the Aboriginal Ethics Sub-Committee.

\section{Materials and methods}

\subsection{Study population}

Potential participants were recruited from remote Aboriginal communities in the Top End of the NT, Darwin (the NT capital city), and the Darwin Correctional Centre. Participants were recruited between 10th November 2010-29th November 2011 when the Therapeutic Goods Administration suspended use of 23vPPV owing to reports of increased adverse reactions following repeated doses of 23vPPV. Recruitment then commenced again between 5th December 2012-7th February 2013. The informed consent process included a discussion using a pictorial flip chart and plain language participant information sheet explaining the study requirements, risks and benefits. Potential participants were only recruited when the study staff felt the requirements were understood. Eligible participants were adults aged 15-59 years, due for a first or second dose of 23vPPV as per the recommended NT schedule (Indigenous adults) or for whom the vaccine was not otherwise contraindicated (non-Indigenous adults). Exclusion criteria included pregnancy or known allergy to any component within 23vPPV. Blood was collected immediately prior to and one month after $23 \mathrm{vPPV}$ vaccination for the following groups: Group 1; first dose
23vPPV, Indigenous adults; Group 2; second dose 23vPPV, Indigenous adults; and Group 3; first dose 23vPPV, non-Indigenous adults. Life course vaccination status was confirmed with the NT adult vaccination database.

\subsection{Measurement of pneumococcal antibody response}

Serotype-specific IgG levels for each of the 23 serotypes contained in 23vPPV were measured by a modified WHO ELISA published previously $[12,13]$.

\subsection{Definition of adequate response}

We defined a priori an adequate response to 23vPPV in this population using a combination of internationally standardised criteria developed for evaluation of immune deficiency $[14,15]$ as well as taking into consideration study population characteristics such as age and chronic illness. An 'adequate' immune response in paired pre- and post-vaccination sera was defined for each vaccine serotype as either:

- $\geq 4$-fold rise in serotype-specific antibody titre; OR

- $\geq 2$-fold rise in serotype-specific antibody titre if the post vaccination concentration of pneumococcal polysaccharide serotype specific antibody was $\geq 1.3 \mu \mathrm{g} / \mathrm{ml}$ and $\leq 4.0 \mu \mathrm{g} / \mathrm{ml} ;$ OR

- a post vaccination pneumococcal polysaccharide serotype specific antibody concentration $>4.0 \mu \mathrm{g} / \mathrm{ml}$ regardless of the fold-rise in titre from pre-vaccination concentration.

An overall positive response to 23vPPV required an adequate response to at least $50 \%$ ( 12 serotypes) of the 23 vaccine serotypes. Comparison of the proportion of participants with an adequate response to $\geq 70 \%$ ( 16 serotypes) of vaccine serotypes was also done according to current AAAAI guidelines for adults [16]. All other responses were defined as an inadequate immune response.

\subsection{Statistical analysis}

Our primary outcome was the comparison of the immune response between first and second dose Indigenous adult recipients, for which our intended sample size was 120 participants per group. We assumed $\geq 85 \%$ of Indigenous adults receiving a first $23 \mathrm{vPPV}$ dose would have an adequate immune response thus providing 93\% power (alpha 0.05 ) to detect an adequate immune response in $\leq 65 \%$ of second dose recipients. We did not adjust for re-use of the control group (Group 1) in comparisons of the immune response with the non-Indigenous first dose recipients (Group 3).

Pearson's Chi-squared test was used to compare the proportion of participants with an adequate immune response between Indigenous participants receiving first dose and second dose 23vPPV (Groups 1 and 2) as the primary analysis, and between Indigenous and non-Indigenous participants receiving first dose 23vPPV (Groups 1 and 3) as a secondary analysis.

Geometric Mean Concentrations (GMCs) with 95\% Confidence Intervals (CIs) for serotype-specific IgG levels were used to compared the pre- and post-vaccination response using a Student's t-test for Groups 1 v 2 and Groups 1 v 3. A p-value $<0.05$ was considered significant.

\section{Results}

A total of 60 first-dose Indigenous participants, 20 s-dose Indigenous participants and 25 first-dose non-Indigenous participants were included in the final analysis. A further 21 participants 
were excluded from the final analysis: six (from Group 1) did not have follow-up blood collected and 15 (13 from Group 1 and two from Group 2) had follow-up blood collected outside the study window of 25-35 days (range 23-97 days). Overall, we did not achieve our intended sample size and were underpowered for the primary analysis.

Table 1 shows the participant characteristics across the groups. Indigenous participants were more likely to be male, and had a wider age range than non-Indigenous participants. Indigenous participants had higher rates of self-reported chronic illness (such as diabetes) (23\%) compared to non-Indigenous participants (16\%), especially in the second dose group (50\%). Self-reported serious medical conditions (such as kidney disease, rheumatic heart disease, bronchiectasis) were similar between Indigenous participants in Groups 1 (12\%) and 2 (10\%) while non-Indigenous participants had no serious medical condition reported. The mean time elapsed between receiving the first and second dose of 23vPPV was 8 years and 9 months for second dose recipients.

\subsection{Poorer adequate response to $23 v P P V$ among Indigenous participants compared to non-Indigenous participants}

Adequate immune responses following 23vPPV were found for $88 \%(n=53 / 60)$ of Indigenous first-dose recipients compared to $70 \%(n=14 / 20)$ of Indigenous second-dose recipients and 100\% $(\mathrm{n}=25)$ of non-Indigenous first-dose recipients (Table 2 ). Although $18 \%$ more Indigenous participants receiving a first dose of $23 \mathrm{vPPV}$ met the a priori criteria for an adequate immune response compared to a second dose 23vPPV, this was not statistically significant ( $p=0.05,95 \% \mathrm{CI}-3 \%$ to $40 \%$ ). Similarly the $-12 \%$ risk difference between Indigenous and non-Indigenous first dose participants was not statistically significant $(\mathrm{p}=0.07,95 \% \mathrm{CI}-20 \%$ to $-4 \%$; Table 3).

Table 1

Demographic characteristics of study participants.

\begin{tabular}{llll}
\hline & $\begin{array}{l}\text { Indigenous 1st } \\
\text { dose }(\mathrm{n}=60)\end{array}$ & $\begin{array}{l}\text { Indigenous 2nd } \\
\text { dose }(\mathrm{n}=20)\end{array}$ & $\begin{array}{l}\text { Non-Indigenous } \\
1 \text { st dose }(\mathrm{n}=25)\end{array}$ \\
\hline $\begin{array}{c}\text { Days post- } \\
\text { vaccination }\end{array}$ & $29(25-35)$ & $28(25-30)$ & $29(25-35)$ \\
$\quad \begin{array}{l}\text { mean (range) } \\
\text { Age mean (range) }\end{array}$ & $34(16-59)$ & $41(26-59)$ & $32(16-41)$ \\
$\begin{array}{c}\text { Proportion male } \\
\text { Chronic illness }\end{array}$ & $34(57 \%)$ & $18(90 \%)$ & $8(32 \%)$ \\
$\quad \begin{array}{c}\mathrm{a} \\
\text { Serious medical }\end{array} \quad$ & $7(13 \%)$ & $10(50 \%)$ & $4(16 \%)$ \\
$\quad$ condition & & $2(10 \%)$ & $0(0 \%)$
\end{tabular}

a Difference between groups significantly different $\mathrm{p}<0.05$
Considering each aspect of the a priori criteria for an adequate immune response to $\geq 12$ (50\%) serotypes, a 4 -fold rise in antibody concentration was found amongst $52 \%$ of Indigenous first-dose recipients whilst $47 \%$ had post vaccination antibody concentrations beyond the $4.0 \mu \mathrm{g} / \mathrm{ml}$ threshold. Fewer second-dose participants met the criteria of a 4 -fold rise $(20 \%)$ or the $4.0 \mu \mathrm{g} / \mathrm{ml}$ threshold (50\%). In contrast, almost all non-Indigenous participants had a 4 -fold rise (96\%) or a post vaccination titre $>4.0 \mu \mathrm{g} /$ $\mathrm{ml}(84 \%)$. The difference in the proportion of participants with a 4-fold rise in antibody concentration was statistically significant for each study group $(\mathrm{p}<0.05)$. Only one participant (Indigenous first-dose) was classified as having an adequate immune response on the basis of a 2-fold rise when the post vaccination antibody concentration was between 1.3 and $4.0 \mu \mathrm{g} / \mathrm{ml}$ (Table 2). As shown in Fig. 1, non-Indigenous first-dose participants had a median adequate response to $21 / 23$ serotypes, which was significantly higher than for Indigenous first-dose participants response to a median $18 / 23$ serotypes $(p=0.0003)$. Indigenous second-dose participants responded lowest to 15 serotypes but this was not significantly different than 1 st dose Indigenous participants.

We also considered the proportion of participants in each group with an adequate response to varying 'thresholds' using three cutoffs for the number of serotypes: $\geq 12$ ( $50 \%$ of serotypes), $\geq 16$ (70\%) and $\geq 21$ (90\%) as a post hoc analysis (Table 3 ). These results show a similar pattern, where an adequate immune response was highest among non-Indigenous first-dose participants for all thresholds, with $60 \%$ producing an adequate response to $\geq 21$ serotypes, followed by Indigenous first-dose and Indigenous seconddose participants (22\% and 15\%, respectively). Using these higher thresholds, the absolute difference in the proportions of adequate responders was 5\% for Indigenous first- versus second-dose participants for $\geq 16$ serotypes ( $95 \% \mathrm{CI}-20 \%$ to $30 \%$, $\mathrm{p}=0.69$ ) and $7 \%$ for $\geq 21$ serotypes ( $95 \% \mathrm{CI}-12 \%$ to $25 \%, \mathrm{p}=0.52$ ). In contrast, the differential was substantially higher when Indigenous first-dose participants were compared with non-Indigenous first-dose participants: absolute difference was $-27 \%$ for $\geq 16$ serotypes $(95 \% \mathrm{CI}$ $-43 \%$ to $-11 \%, \mathrm{p}=0.01$ ) and $38 \%$ for $\geq 21$ serotypes $(95 \% \mathrm{CI}-60 \%$ to $-16 \%, p=0.006)$. This suggests that while repeat $23 \mathrm{vPPV}$ among Indigenous participants did not appear to significantly reduce pneumococcal antibody levels, Indigenous participants had lower responses to a single $23 \mathrm{vPPV}$ dose than non-Indigenous participants.

We conducted secondary post hoc analyses where we included participants who had initially been excluded because their postvaccination blood collection was outside the study window. This increased the number of participants to: 73 Indigenous adults receiving their first $23 \mathrm{vPPV}$ dose (increase $=13$ ); 22 Indigenous adults receiving a second $23 \mathrm{vPPV}$ dose (increase $=2$ ); and 25

Table 2

Proportion of participants achieving adequate response following 23vPPV.

\begin{tabular}{|c|c|c|c|c|c|c|c|c|}
\hline \multirow[b]{2}{*}{ Group } & \multicolumn{2}{|c|}{$\begin{array}{l}\text { Overall adequate response } \\
\text { (any) }\end{array}$} & \multicolumn{2}{|l|}{$\geq 4$-fold rise } & \multicolumn{2}{|c|}{$\begin{array}{l}\geq 2 \text {-fold rise and }[\operatorname{IgG}] \\
\geq 1.3 \text { and } \leq 4.0 \mu \mathrm{g} / \mathrm{ml}\end{array}$} & \multicolumn{2}{|c|}{ Post-vaccination $\geq 4.0 \mu \mathrm{g} / \mathrm{ml}$} \\
\hline & $\begin{array}{l}\geq 12 \text { serotypes } \\
(\%)\end{array}$ & $\begin{array}{l}\text { Median } \\
\text { number } \\
\text { of } \\
\text { serotypes }\end{array}$ & $\begin{array}{l}\geq 12 \text { serotypes } \\
(\%)\end{array}$ & $\begin{array}{l}\text { Median } \\
\text { number } \\
\text { of } \\
\text { serotypes }\end{array}$ & $\begin{array}{l}\geq 12 \text { serotypes } \\
(\%)\end{array}$ & $\begin{array}{l}\text { Median } \\
\text { number } \\
\text { of } \\
\text { serotypes }\end{array}$ & $\begin{array}{l}\geq 12 \text { serotypes } \\
(\%)\end{array}$ & $\begin{array}{l}\text { Median } \\
\text { number } \\
\text { of } \\
\text { serotypes }\end{array}$ \\
\hline Indigenous 1 st dose $(n=60)$ & $53(88 \%)$ & 18 & $31(52 \%)$ & 12 & $1(2 \%)$ & 5 & $28(47 \%)$ & 11 \\
\hline Indigenous 2 nd dose $(n=20)$ & $14(70 \%)$ & 16 & $2(20 \%)$ & 12 & $0(0 \%)$ & 3 & $10(50 \%)$ & 6 \\
\hline $\begin{array}{l}\text { Non-Indigenous 1st dose } \\
\quad(n=25)\end{array}$ & $25(100 \%)$ & 21 & $24(96 \%)$ & 14 & $0(0 \%)$ & 5 & $21(84 \%)$ & 17 \\
\hline Indigenous 1st vs 2nd dose & \multicolumn{2}{|l|}{$18 \%(-3$ to $40 \%)$} & \multicolumn{2}{|l|}{$42 \%$ (23 to $60 \%)$} & \multicolumn{2}{|l|}{$2 \%(-2$ to $5 \%)$} & \multicolumn{2}{|c|}{$-3 \%(-29$ to $22 \%)$} \\
\hline p-value & \multicolumn{2}{|l|}{0.05} & \multicolumn{2}{|l|}{0.001} & \multicolumn{2}{|l|}{0.56} & \multicolumn{2}{|c|}{0.796} \\
\hline $\begin{array}{l}\text { Indigenous vs non-Indigenous } \\
\text { 1st dose }\end{array}$ & \multicolumn{2}{|c|}{$-12 \%(-20$ to $-4 \%)$} & \multicolumn{2}{|c|}{$-44 \%(-59$ to $-30 \%)$} & \multicolumn{2}{|l|}{$2 \%(-2$ to $5 \%)$} & \multicolumn{2}{|c|}{$-37 \%(-56$ to $-18 \%)$} \\
\hline p-value & \multicolumn{2}{|l|}{0.07} & \multicolumn{2}{|l|}{0.0001} & \multicolumn{2}{|l|}{0.516} & \multicolumn{2}{|l|}{0.002} \\
\hline
\end{tabular}


Table 3

Participants with an adequate immune response according to various thresholds.

\begin{tabular}{|c|c|c|c|}
\hline \multirow[b]{2}{*}{ Group } & \multicolumn{3}{|c|}{ Participants with adequate response to } \\
\hline & $\geq 12$ serotypes & $\geq 16$ serotypes & $\geq 21$ serotypes \\
\hline Indigenous 1st dose $(n=60)$ & $53(88 \%)$ & $39(65 \%)$ & $13(22 \%)$ \\
\hline Indigenous 2nd dose $(n=20)$ & $14(70 \%)$ & $12(60 \%)$ & $3(15 \%)$ \\
\hline Non-Indigenous 1st dose $(\mathrm{n}=25)$ & $25(100 \%)$ & $23(92 \%)$ & $15(60 \%)$ \\
\hline \multicolumn{4}{|l|}{ Indigenous 1st vs 2nd dose } \\
\hline Risk difference (95\% CI) & $18 \%(-3$ to $40 \%)$ & $5 \%(-20 \%$ to $30 \%)$ & $7 \%(-12 \%$ to $25 \%)$ \\
\hline p-value & 0.05 & 0.69 & 0.52 \\
\hline \multicolumn{4}{|l|}{ Indigenous vs non-Indigenous 1 st dose } \\
\hline Risk difference (95\% CI) & $-12 \%$ ( -20 to $-4 \%)$ & $-27 \%(-43 \%$ to $-11 \%)$ & $-38 \%(-60 \%$ to $-16 \%)$ \\
\hline p-value & 0.07 & 0.01 & 0.006 \\
\hline
\end{tabular}

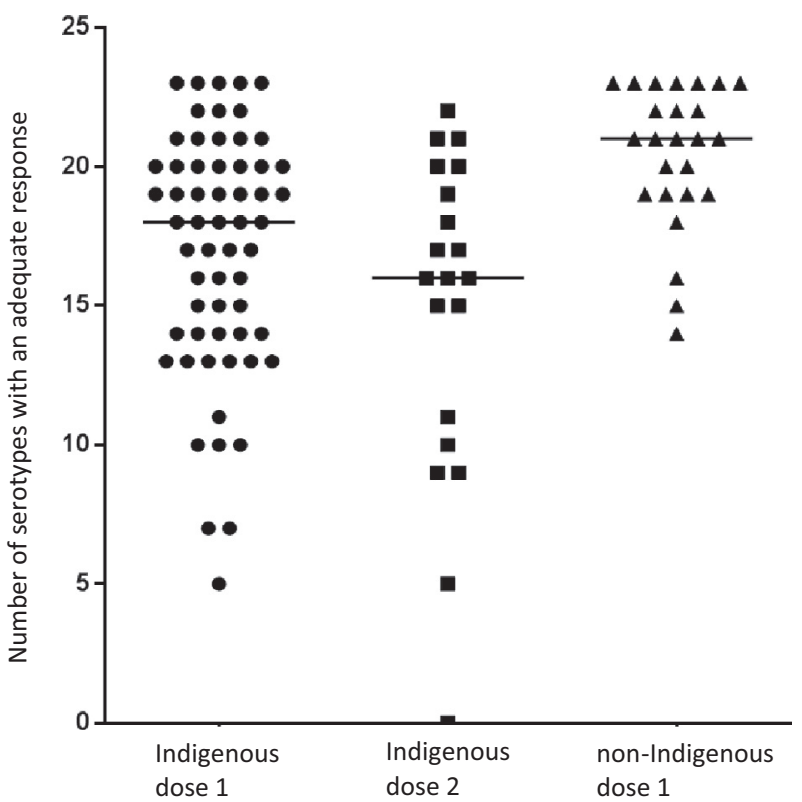

Fig. 1. Number of serotypes with an adequate immune response for Indigenous 1st or 2 nd dose 23vPPV recipients and non-Indigenous 1st dose recipients. Each data point represents one member of the study group; the solid line represents the median.

non-Indigenous adults receiving their first 23vPPV dose (no change). Under this scenario, the results remained similar with no significant difference in the proportion of individuals with an adequate response using our primary endpoint: $89 \%$ of Indigenous adults mounted an adequate response following first dose 23vPPV (65/73) compared to $73 \%$ having an adequate response following a second dose of 23vPPV (16/22; $\mathrm{p}=0.058)$.

\subsection{Effect of age and gender on response to $23 v P P V$}

We stratified the groups based on age and gender, including the 15 participants who had delayed post-vaccination blood collection. No difference in the proportion of individuals with an adequate response using any of the criteria was observed when comparing Indigenous and non-Indigenous participants receiving a first dose of $23 \mathrm{vPPV}$, or between Indigenous participants given a first or second dose of 23vPPV (Table 4). However, for participants $\geq 41$ years of age (oldest age in the non-Indigenous group), there was a significant difference in the median number of serotypes responded to between first-dose Indigenous (18 serotypes) and non-Indigenous participants only ( 21 serotypes, $\mathrm{p}=0.0001$; Fig. 3 ). For participants $>41$ years old, Indigenous first dose recipients responded to a significantly higher number of serotypes (20) compared to Indigenous second dose recipients $(15 ; \mathrm{p}<0.0019)$. There were no non-
Table 4

Proportion of participants achieving adequate response following 23vPPV; by age and gender (including participants with delayed blood collection, $\mathrm{n}=120$ ).

\begin{tabular}{|c|c|c|}
\hline \multirow[b]{2}{*}{ Group } & \multicolumn{2}{|c|}{ Overall adequate response (any) } \\
\hline & $\geq 12$ serotypes (\%) & $\begin{array}{l}\text { Median number } \\
\text { of serotypes }\end{array}$ \\
\hline \multicolumn{3}{|l|}{ Age } \\
\hline $\begin{array}{l}\text { Indigenous } 1 \text { st dose } \\
\leq 41 \text { years }(N=58) \\
>41 \text { years }(N=15)\end{array}$ & $\begin{array}{l}52(90) \\
13(87)\end{array}$ & $\begin{array}{l}17 \\
18\end{array}$ \\
\hline $\begin{array}{l}\text { Indigenous } 2 \text { nd dose } \\
\leq 41 \text { years }(N=12) \\
>41 \text { years }(N=10)\end{array}$ & $\begin{array}{l}10(83) \\
6(60)\end{array}$ & $\begin{array}{l}18 \\
12\end{array}$ \\
\hline $\begin{array}{l}\text { Non-Indigenous } 1 \text { st } \\
\leq 41 \text { years }(N=25) \\
>41 \text { years }(N=0)\end{array}$ & $\begin{array}{l}25(100) \\
-\end{array}$ & $\begin{array}{l}20 \\
-\end{array}$ \\
\hline $\begin{array}{l}\text { Indigenous } 1 \text { st vs } 2 \text { no } \\
\leq 41 \text { years } \\
>41 \text { years }\end{array}$ & $\begin{array}{c}\text { Ialue } \\
0.53 \\
0.13\end{array}$ & \\
\hline $\begin{array}{l}\text { Indigenous } v s \text { non-In } \\
\leq 41 \text { years } \\
>41 \text { years }\end{array}$ & $\begin{array}{l}1 \text { st dose p-value } \\
0.095 \\
\text { NA }\end{array}$ & \\
\hline \multicolumn{3}{|l|}{ Gender } \\
\hline $\begin{array}{l}\text { Indigenous } 1 \text { st dose } \\
\text { Male }(\mathrm{N}=40) \\
\text { Female }(\mathrm{N}=33)\end{array}$ & $\begin{array}{l}38(95) \\
27(82)\end{array}$ & $\begin{array}{l}18 \\
16\end{array}$ \\
\hline $\begin{array}{l}\text { Indigenous 2nd dose } \\
\text { Male }(\mathrm{N}=19) \\
\text { Female }(\mathrm{N}=3)\end{array}$ & $\begin{array}{l}13(68) \\
3(100)\end{array}$ & $\begin{array}{l}15 \\
18\end{array}$ \\
\hline $\begin{array}{l}\text { Non-Indigenous } 1 \text { st } \\
\text { Male }(\mathrm{N}=7) \\
\text { Female }(\mathrm{N}=18)\end{array}$ & $\begin{array}{l}7(100) \\
18(100)\end{array}$ & $\begin{array}{l}20 \\
21\end{array}$ \\
\hline $\begin{array}{l}\text { Indigenous 1st vs } 2 \text { no } \\
\text { Male } \\
0.42 \\
\text { Female }\end{array}$ & $\begin{array}{l}\text { Ialue } \\
0.005\end{array}$ & \\
\hline $\begin{array}{l}\text { Indigenous vs non-In } \\
\text { Male } \\
\text { Female }\end{array}$ & $\begin{array}{l}1 \text { st dose } \mathrm{p} \text {-value } \\
0.545 \\
0.054\end{array}$ & \\
\hline
\end{tabular}

Indigenous participants $>41$ years of age so we could not compare with the other Indigenous groups.

A significantly lower proportion of males had an adequate response in the second dose Indigenous group (68\%) compared to first dose Indigenous recipients $(95 \%, p=0.0053$; Table 4$)$. No differences were found for males or females for all other comparisons. Similarly, male Indigenous second dose recipients responded with a significantly lower median number of serotypes (16) compared to Indigenous first dose recipients (19; $\mathrm{p}=0.037$; Fig. 3 ). For female participants, Indigenous first dose recipients responded to a significantly lower median number of serotypes (18) compared to nonIndigenous participants $(21 ; \mathrm{p}=0.0001)$. 


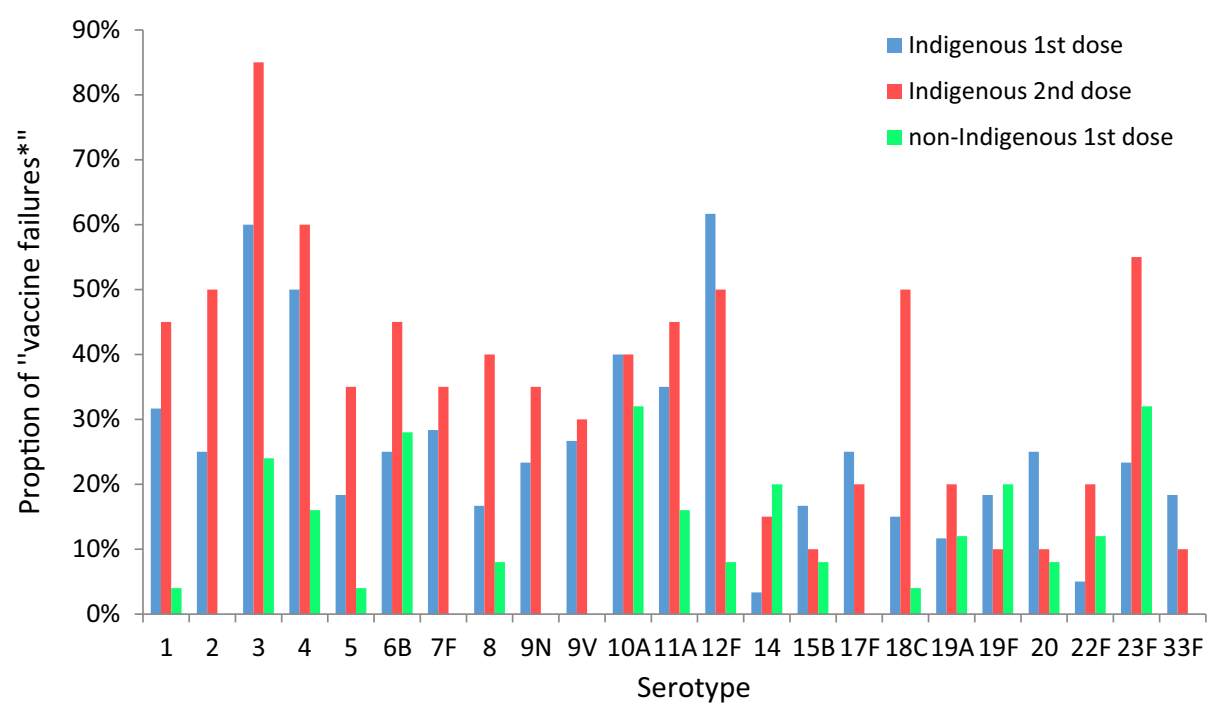

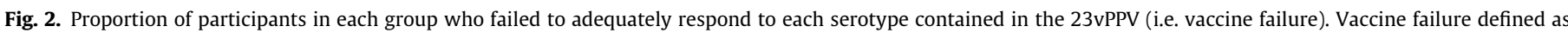
participants who failed to meet the definition of an adequate immune response for the specific serotype.
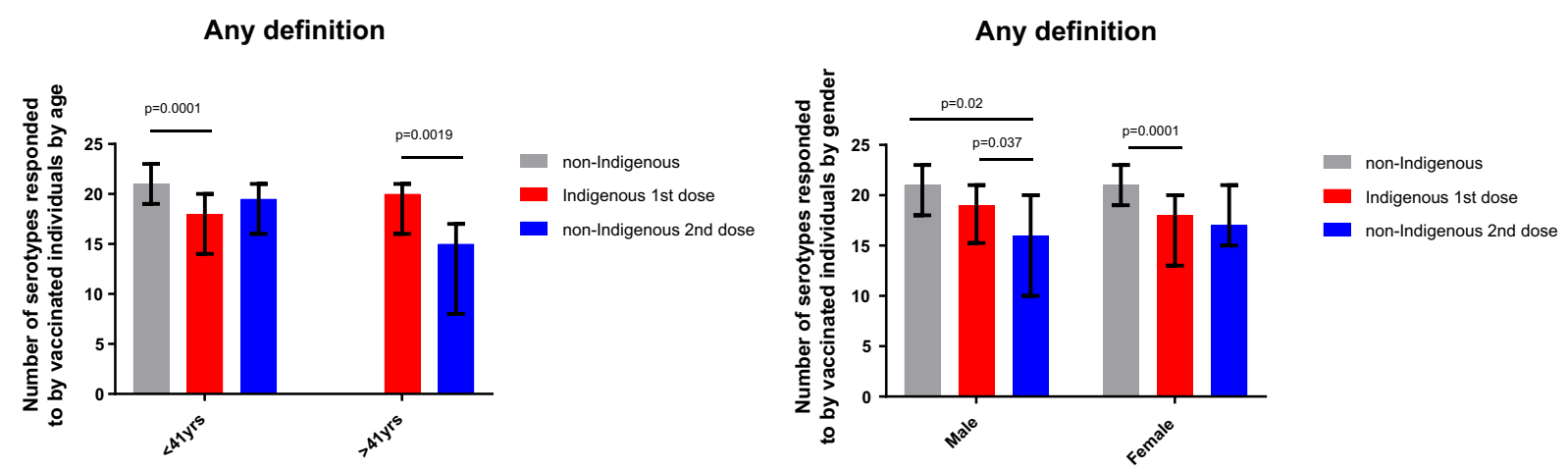

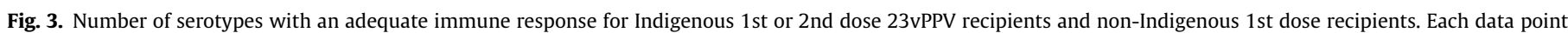
represents one member of the study group; the solid line represents the median. (A) By age. (B) By gender.

\subsection{Vaccine failures}

We classified inadequate vaccine response by serotype as a secondary analysis, showing the proportion of participants who failed to meet the definition of an adequate immune response for the specific serotype, referred to here as "vaccine failure". Whilst noting that numbers were small, and acknowledging that failure to achieve the pre-specified immune response may not mean that the vaccine will fail to protect an individual from disease, we found the proportion of vaccine failures amongst Indigenous first-dose recipients compared to Indigenous second-dose participants was higher for all but seven of the 23 serotypes (Fig. 2). Serotype 3 was the most common serotype for which Indigenous participants failed to mount an adequate immune response $(60 \%$ and $85 \%$ of participants in Groups 1 and 2, respectively) while for nonIndigenous participants, vaccine failures were highest for serotypes 14 and $19 \mathrm{~F}$ (both 20\%) compared to Indigenous 1st dose (5\% and $14 \%$, respectively) and 2 nd dose (19\% and 9\%, respectively) recipients.

\subsection{Absolute levels of serotype-specific IgG were similar across all groups}

Baseline serotype-specific IgG geometric mean concentrations (GMCs) were similar across Indigenous and non-Indigenous participants who had not yet received 23vPPV (Table 5). As expected,
Indigenous second-dose participants had higher baseline IgG levels for most 23vPPV serotypes. Following 23vPPV, both Indigenous and non-Indigenous groups receiving their first dose had higher post-vaccination serotype-specific IgG levels for a majority of serotypes than participants in the second-dose group. Serotypespecific IgG was significantly higher in Indigenous first-dose compared to Indigenous second-dose groups only for serotype 8 $(p=0.02)$. Non-Indigenous first-dose participants achieved higher serotype-specific IgG than Indigenous first-dose participants for most serotypes, although Indigenous first-dose participants had significantly higher IgG levels for serotypes $19 \mathrm{~A}(\mathrm{p}=0.003), 22 \mathrm{~F}$ $(\mathrm{p}=0.002)$ and $23 \mathrm{~F}(\mathrm{p}=0.009)$. Moreover, Indigenous participants receiving their second dose had the smallest post-vaccination fold-difference across all serotypes (except serotype 12F; Table 5), most likely due to the higher baseline levels of serotype-specific IgG. Non-Indigenous first dose participants had the highest folddifference across all serotypes apart from $19 \mathrm{~F}$ and $33 \mathrm{~F}$, where Indigenous first-dose participants had a higher fold rise.

\section{Discussion}

This is the first study to compare the immune response of Australian Indigenous adults receiving a first or second dose of 23vPPV with non-Indigenous Australians. Despite our small sample size, our study highlights a serious concern in relation to the immune response to 23vPPV among Indigenous Australians. Our findings 
Table 5

Serotype-specific IgG geometric mean concentration (95\% confidence intervals) pre and post 23vPPV vaccination, by participant group.

\begin{tabular}{|c|c|c|c|c|c|c|c|c|c|}
\hline \multirow[b]{2}{*}{ Serotype } & \multicolumn{3}{|c|}{ Indigenous 1 st dose $(\mathrm{n}=60)$} & \multicolumn{3}{|c|}{ Indigenous 2nd dose $(\mathrm{n}=20)$} & \multicolumn{3}{|c|}{ Non-Indigenous 1 st dose $(n=25)$} \\
\hline & Pre & Post & $\mathrm{FR}^{\mathrm{a}}$ & Pre & Post & FR & Pre & Post & FR \\
\hline 1 & $0.47(0.37,0.60)$ & $2.57(1.85,3.56)$ & 10.2 & $1.21(0.74,2.00)$ & $2.63(1.46,4.71)$ & 3.4 & $0.37(0.27,0.52)$ & $8.39(5.06,13.92)$ & 38.1 \\
\hline 2 & $0.65(0.50,0.85)$ & $4.46(3.12,6.36)$ & 11.5 & $1.56(1.16,2.09)$ & $3.43(2.11,5.56)$ & 4.7 & $0.95(0.65,1.40)$ & $14.79(8.53,25.63)$ & 25.3 \\
\hline 3 & $0.66(0.53,0.82)$ & $1.50(1.14,1.97)$ & 3.1 & $0.63(0.42,0.93)$ & $1.14(0.71,1.83)$ & 2.3 & $0.71(0.47,1.08)$ & $3.14(2.04,4.84)$ & 7.3 \\
\hline 4 & $0.30(0.23,0.38)$ & $1.08(0.79,1.49)$ & 5.6 & $0.81(0.46,1.45)$ & $1.53(0.81,2.90)$ & 2.5 & $0.24(0.15,0.38)$ & $2.10(1.43,3.08)$ & 14.7 \\
\hline 5 & $0.77(0.61,0.96)$ & $4.63(3.49,6.15)$ & 12.4 & $1.33(0.77,2.33)$ & $3.55(1.74,7.24)$ & 4.6 & $0.55(0.40,0.75)$ & $5.83(3.58,9.51)$ & 16.0 \\
\hline $6 B$ & $0.86(0.65,1.13)$ & $4.19(2.89,6.09)$ & 9.3 & $1.43(0.81,2.54)$ & $2.98(1.60,5.57)$ & 3.5 & $0.42(0.31,0.58)$ & $2.82(1.71,4.67)$ & 12.2 \\
\hline $7 \mathrm{~F}$ & $1.00(0.80,1.25)$ & $3.82(2.89,5.03)$ & 8.2 & $1.21(0.80,1.85)$ & $3.44(2.14,5.53)$ & 3.7 & $0.50(0.33,0.76)$ & $9.47(6.43,13.94)$ & 26.4 \\
\hline 8 & $0.74(0.54,1.01)$ & $4.74(3.54,6.34)$ & 14.9 & $1.10(0.75,1.63)$ & $2.56(1.49,4.40)$ & 2.7 & $0.50(0.32,0.79)$ & $10.87(6.35,18.61)$ & 36.4 \\
\hline $9 N$ & $0.74(0.57,0.96)$ & $4.19(3.13,5.61)$ & 10.8 & $1.83(1.12,2.99)$ & $4.93(2.75,8.82)$ & 3.8 & $0.47(0.29,0.74)$ & $6.81(4.75,9.76)$ & 25.3 \\
\hline $9 \mathrm{~V}$ & $0.78(0.62,0.98)$ & $3.42(2.60,4.51)$ & 7.5 & $1.19(0.67,2.10)$ & $3.01(1.63,5.59)$ & 4.8 & $0.61(0.44,0.86)$ & $5.02(3.58,7.03)$ & 11.8 \\
\hline $10 \mathrm{~A}$ & $1.19(0.96,1.49)$ & $3.05(2.35,3.94)$ & 3.7 & $1.36(0.81,2.28)$ & $3.01(1.69,5.36)$ & 3.2 & $0.67(0.48,0.94)$ & $2.85(1.90,4.28)$ & 5.6 \\
\hline $11 \mathrm{~A}$ & $0.97(0.75,1.26)$ & $3.14(2.45,4.02)$ & 6.9 & $0.86(0.57,1.29)$ & $2.39(1.46,3.92)$ & 4.5 & $1.17(0.67,2.06)$ & $5.03(3.25,7.79)$ & 8.7 \\
\hline $12 \mathrm{~F}$ & $0.25(0.20,0.31)$ & $0.83(0.62,1.13)$ & 7.9 & $0.36(0.23,0.56)$ & $1.13(0.66,1.94)$ & 8.5 & $0.13(0.09,0.18)$ & $1.60(0.99,2.59)$ & 18.4 \\
\hline 14 & $2.52(1.69,3.76)$ & $14.02(10.11,19.44)$ & 13.2 & $9.17(5.29,15.89)$ & $16.07(9.47,27.26)$ & 11.2 & $1.00(0.54,1.86)$ & $7.64(3.75,15.56)$ & 13.3 \\
\hline $15 B$ & $1.70(1.29,2.24)$ & $8.02(5.88,10.95)$ & 7.6 & $4.03(2.46,6.60)$ & $10.07(6.12,16.56)$ & 5.1 & $1.25(0.76,2.07)$ & $10.01(6.43,15.57)$ & 12.9 \\
\hline $17 \mathrm{~F}$ & $0.59(0.47,0.74)$ & $3.36(2.40,4.72)$ & 11.4 & $1.51(1.01,2.26)$ & $4.70(3.29,6.70)$ & 5.0 & $0.45(0.32,0.63)$ & $8.20(5.78,11.65)$ & 24.0 \\
\hline $18 \mathrm{C}$ & $0.92(0.69,1.22)$ & $4.60(3.50,6.06)$ & 8.1 & $1.14(0.68,1.90)$ & $2.91(1.65,5.13)$ & 4.5 & $0.59(0.39,0.89)$ & $7.76(5.30,11.37)$ & 20.5 \\
\hline $19 A$ & $7.31(5.87,9.10)$ & $10.51(8.30,13.31)$ & 2.0 & $5.35(3.22,8.89)$ & $7.92(4.75,13.22)$ & 1.9 & $2.71(1.94,3.79)$ & $6.86(4.69,10.05)$ & 3.7 \\
\hline $19 \mathrm{~F}$ & $2.16(1.70,2.75)$ & $7.89(5.85,10.63)$ & 7.1 & $4.83(3.03,7.68)$ & $9.00(5.41,14.95)$ & 2.7 & $0.94(0.66,1.33)$ & $4.79(2.98,7.70)$ & 6.6 \\
\hline 20 & $0.76(0.61,0.95)$ & $3.81(2.75,5.26)$ & 8.1 & $2.42(1.34,4.38)$ & $6.56(3.54,12.17)$ & 3.5 & $1.36(0.91,2.03)$ & $9.39(6.25,14.11)$ & 9.2 \\
\hline $22 \mathrm{~F}$ & $5.42(3.75,7.83)$ & $13.20(10.03,17.35)$ & 4.3 & $5.41(2.92,10.02)$ & $10.42(5.36,20.24)$ & 3.6 & $1.06(0.78,1.46)$ & $6.27(4.29,9.17)$ & 11.1 \\
\hline $23 \mathrm{~F}$ & $0.84(0.65,1.07)$ & $3.71(2.89,4.77)$ & 9.0 & $1.54(1.00,2.35)$ & $2.98(1.68,5.27)$ & 2.8 & $0.33(0.22,0.51)$ & $1.89(1.00,3.59)$ & 11.4 \\
\hline $33 \mathrm{~F}$ & $1.39(1.06,1.82)$ & $8.24(5.74,11.83)$ & 12.5 & $2.79(1.73,4.49)$ & $7.89(4.73,13.15)$ & 5.3 & $1.78(1.17,2.71)$ & $16.18(11.43,22.91)$ & 12.3 \\
\hline
\end{tabular}

${ }^{\mathrm{a}} \mathrm{FR}=$ fold rise from pre to post-vaccination.

suggest that Indigenous participants have a poorer response to 23vPPV compared to their non-Indigenous counterparts, while Indigenous adults receiving a second dose of $23 \mathrm{vPPV}$ produced a poorer immune response when compared to Indigenous adults receiving the vaccine for the first time. As this is the first study to be conducted in this setting, we may have been overly conservative in our a priori definition that an adequate response should include at least $50 \%$ of the serotypes contained within the 23vPPV. As a post hoc analysis, we found that setting the benchmark of an adequate response to $70 \%(\geq 16)$ of the 23vPPV serotypes (as per AAAAI guidelines for immunodeficiency) or $90 \%(\geq 21)$ both showed Indigenous first-dose recipients had poorer immunological responses than non-Indigenous first dose 23vPPV recipients.

The effect of 23vPPV on the immune response in children and adults, especially following a repeat doses, has yielded conflicting data $[6-8,17]$. Some of these studies used pooled immune response data within participant groups for comparison rather than individual level data, making the results difficult to compare. In the Alaskan study, high rates of chronic illness were also observed but with much lower rates of invasive pneumococcal disease than our study population [6]. Lower antibody concentrations in our population [18] suggest that it may be the failure to produce adequate antibody following vaccination as the key factor in the continued susceptibility to disease (and failure to observe a reduction in rates of invasive pneumococcal disease) compared with those in the Alaskan study.

Furthermore, the non-randomised nature for some of these studies make interpretation of the results difficult. In a recent study in Fiji, we found that while hyporesponsiveness was detected in 23vPPV-vaccinated children after a small challenge dose of $23 \mathrm{vPPV}$ ( $20 \%$ dose) at 18 months of age, their immune status had normalised in response to a PCV13 booster dose by 5 years of age [11]. In the current study, despite the mean time since previous 23vPPV among Indigenous participants being 8 years and nine months, there was still a trend towards reduced responsiveness, although not significant $(p=0.05)$, suggesting a residual impact of the first 23vPPV dose. Although repeat 23vPPV among Indigenous participants yielded a slightly poorer response compared to first time vaccinees, the difference in response was greatest between Indigenous and non-Indigenous participants.
Nasopharyngeal carriage of pneumococcus at the time of vaccination is known to induce poorer antibody and OPA levels, and is typically higher among Indigenous compared to non-Indigenous Australians. A study in Indigenous adults in the Northern Territory of Australia found pneumococcal nasopharyngeal carriage in $26 \%$ [19] of adults, and may be one reason for the reduced response level among Indigenous adults. Furthermore, 23vPPV has little impact on pneumococcal vaccine-type carriage [20], likely contributing to the suboptimal impact on IPD in this population.

Non-response to some pneumococcal serotypes within individuals $[21,22]$ has been documented previously. Differential immune responses across ethnic groups has also been demonstrated, as well as across serotypes [23]. Furthermore, individuals with chronic illness (which were over-represented in our second dose Indigenous participants) are unlikely to achieve the same level of protective efficacy of $23 \mathrm{vPPV}$ as do healthy adults [18]. We were unable to adjust for the level of chronic illness in our study due to small sample size. Nevertheless, our data supports these findings and may provide some explanation as to the failure in demonstrating a reduction in the high rates of pneumococcal disease experienced throughout life in our study population despite increasing coverage with $23 \mathrm{vPPV}$ [1]. Our results suggest that intrinsic genetic differences between Indigenous and nonIndigenous populations may affect immune responsiveness to $23 \mathrm{vPPV}$, although this needs to be explored in more detail. It is known that the response to influenza vaccine is lower among Indigenous adults due to differential expression in certain HLA genes [24]. While we were unable to rule out other immune response defects in our study population, measurement of functional immunity by opsonophagocytosis and numbers of serotype-specific memory B cells may provide further insights into the mechanisms for the reduced response among Indigenous Australians adults.

Response to vaccines is known to be influenced by age and gender. In our study, non-Indigenous participants of young age ( $\leq 41$ years of age) and being female had the highest response to $23 \mathrm{vPPV}$ compared to Indigenous first dose recipients while older (>41 years) male Indigenous first dose participants had higher responses compared to their second dose counterparts. This is likely due to the overall increased co-morbidities observed in 
second dose Indigenous participants. However, we did not observe any effect of gender on the response of each group to $23 \mathrm{vPPV}$, although for both males and females, non-Indigenous participants responded highest followed by Indigenous first dose and second recipients.

It is possible that our a priori requirement for an adequate response against 12 serotypes may have been too conservative. Given that the 23vPPV covers $74 \%$ of known serotypes in our Indigenous Australian population [1] with an estimated vaccine efficacy of $\sim 74 \%$ against IPD, a response to a larger number of serotypes such as 16 or 21 may be more appropriate. A more stringent requirement would be in line with the AAAAI definition of an adequate response to $70 \%$ or 16 serotypes in adults [25]. Based on these definitions, indigenous second dose recipients responded the lowest to 23vPPV. Our rationale for setting an a priori definition of an adequate immune response considered several factors given that the protective threshold of serotype-specific $\operatorname{IgG}$ in adults, or following $23 \mathrm{vPPV}$, is unknown. A number of criteria have been described for normal response to 23vPPV [26-28]. Typically, immune response to $23 \mathrm{vPPV}$ is based on a two-four-fold rise in serotype-specific IgG and/or a post-immunisation titre $\geq 1.3 \mu \mathrm{g} /$ $\mathrm{ml}$ [29]. Indeed, serotype-specific IgG levels across all groups in this study were above $1.3 \mu \mathrm{g} / \mathrm{ml}$. Therefore, analysis based purely on group IgG GMCs and not on defined criteria to respond to 23vPPV may potentially mask groups of individuals with an inadequate response [30]. Our definition therefore required both an adequate rise in post-vaccination antibody titre and a postvaccination antibody titre to be above a critical threshold for a given number of serotypes, based on data from a limited number of adult studies [21,31] and expert opinion [16].

A number of limitations were associated with our study. The sample size was lower than expected, particularly for the second dose 23vPPV group. Recruitment for this group was stalled for 9 months due to an interim recommendation by the Therapeutic Goods Administration of Australia advising against the administration of second or subsequent vaccine doses whilst an investigation into elevated rates of significant local reactions was undertaken [32]. The primary definition used in this study was based on AAAAI guidelines for infants less than 5 years of age (i.e. response to $\geq 50 \%$ of serotypes) and was not as sensitive to detect inadequate response, and so may have masked any true hyporesponse in this study population.

In light of these findings, the current recommendation of 23vPPV immunisation for Indigenous adults may need reconsidering. Furthermore, strategies to improve 23vPPV uptake within this population should also be a priority. The licensure of new conjugate vaccines (PCV13) for use in older adults may be one way to improve the magnitude and duration of immunity in this population. In the Northern Territory, PCV13 has since replaced 23vPPV for Indigenous infants at 18 months of age, and should provide more effective boosting of immunity as well as impact on carriage. The current issues faced with the use of $23 \mathrm{vPPV}$, especially in highrisk populations such as those individuals in our study, highlights the need for a robust vaccination programme in these settings.

\section{Conclusion}

Taken together, our data has demonstrated a poorer response to a first dose 23vPPV in Indigenous adults compared to nonIndigenous adults in Australia, as well as a reduced immune response for those receiving a second dose 23vPPV compared to their first dose. Confirmation of the immunogenicity of future pneumococcal vaccine programs is important, particularly for Indigenous Australian adults. We propose that in the context of the current 23vPPV vaccination program in this setting, standardized and well-recognised definitions of an adequate immune response such as those by AAAAI be used in conjunction with serotypespecific IgG GMCs to determine 23vPPV responsiveness in high-risk settings.

\section{References}

[1] Moberley S, Krause V, Cook H, Mulholland K, Carapetis J, Torzillo P, et al. Failure to vaccinate or failure of vaccine? Effectiveness of the 23-valent pneumococcal polysaccharide vaccine program in Indigenous adults in the Northern Territory of Australia. Vaccine 2010;28:2296-301.

[2] Torzillo PJ, Hanna JN, Morey F, Gratten M, Dixon J, Erlich J. Invasive pneumococcal disease in central Australia. Med J Aust 1995;162:182-6.

[3] Torzillo PJ, Morey F, Gratten M, Murphy D, Matters R, Dixon J. Changing epidemiology of invasive pneumococcal disease in central Australia prior to conjugate vaccine: a 16-year study. Vaccine 2007;25:2375-8.

[4] CDC. What's new in immunisation? Changes to the Australian and Northern Territory Standard Vaccination Schedules. p. 2000. The Northern Territory Disease Control Bulletin.

[5] The Australian Immunisation Handbook. 9th ed. National Health and Medical Research Council; 2008.

[6] Hammitt LL, Bulkow LR, Singleton RJ, Nuorti JP, Hummel KB, Miernyk KM, et al. Repeat revaccination with 23-valent pneumococcal polysaccharide vaccine among adults aged 55-74 years living in Alaska: no evidence of hyporesponsiveness. Vaccine 2011;29:2287-95.

[7] Manoff SB, Liss C, Caulfield MJ, Marchese RD, Silber J, Boslego J, et al. Revaccination with a 23-valent pneumococcal polysaccharide vaccine induces elevated and persistent functional antibody responses in adults aged $65>$ or $=$ years. J Infect Dis 2010;201:525-33.

[8] Musher DM, Manof SB, Liss C, McFetridge RD, Marchese RD, Bushnell B, et al. Safety and antibody response, including antibody persistence for 5 years, after primary vaccination or revaccination with pneumococcal polysaccharide vaccine in middle-aged and older adults. J Infect Dis 2010;201:516-24.

[9] Torling J, Hedlund J, Konradsen HB, Ortqvist A. Revaccination with the 23valent pneumococcal polysaccharide vaccine in middle-aged and elderly persons previously treated for pneumonia. Vaccine 2003:22:96-103.

[10] Russell FM, Carapetis JR, Balloch A, Licciardi PV, Jenney AW, Tikoduadua L, et al. Hyporesponsiveness to re-challenge dose following pneumococcal polysaccharide vaccine at 12 months of age, a randomized controlled trial. Vaccine 2010;28:3341-9.

[11] Licciardi PV, Toh ZQ, Clutterbuck EA, Balloch A, Marimla RA, Tikkanen L, et al. No long-term evidence of hyporesponsiveness after use of pneumococcal conjugate vaccine in children previously immunized with pneumococcal polysaccharide vaccine. J Allergy Clin Immunol 2016;137(1772-9):e11.

[12] Balloch A, Licciardi PV, Leach A, Nurkka A, Tang ML. Results from an interlaboratory comparison of pneumococcal serotype-specific IgG measurement and critical parameters that affect assay performance. Vaccine 2010;28:1333-40

[13] Wernette CM, Frasch CE, Madore D, Carlone G, Goldblatt D, Plikaytis B, et al Enzyme-linked immunosorbent assay for quantitation of human antibodies to pneumococcal polysaccharides. Clin Diagn Lab Immunol 2003;10:514-9.

[14] Hare ND, Smith BJ, Ballas ZK. Antibody response to pneumococcal vaccination as a function of preimmunization titer. J Allergy Clin Immunol 2009;123:195-200.

[15] Ballow M. Vaccines in the assessment of patients for immune deficiency. Allergy Clin Immunol 2012;130(283-4):e5.

[16] Orange JS, Ballow M, Stiehm ER, Ballas ZK, Chinen J, De La Morena M, et al. Use and interpretation of diagnostic vaccination in primary immunodeficiency: a working group report of the basic and clinical immunology interest section of the American Academy of Allergy, Asthma \& Immunology. J Allergy Clin Immunol 2012;130:S1-S24.

[17] Clutterbuck EA, Lazarus R, Yu LM, Bowman J, Bateman EA, Diggle L, et al. Pneumococcal conjugate and plain polysaccharide vaccines have divergent effects on antigen-specific B cells. J Infect Dis 2012;205:1408-16.

[18] Moberley S, Holden J, Tatham DP, Andrews RM. Vaccines for preventing pneumococcal infection in adults. The Cochrane database of systematic reviews 2013:CD000422.

[19] Mackenzie GA, Leach AJ, Carapetis JR, Fisher J, Morris PS. Epidemiology of nasopharyngeal carriage of respiratory bacterial pathogens in children and adults: cross-sectional surveys in a population with high rates of pneumococcal disease. BMC Infect Dis 2010:10:304.

[20] Russell FM, Carapetis JR, Satzke C, Tikoduadua L, Waqatakirewa L, Chandra R, et al. Pneumococcal nasopharyngeal carriage following reduced doses of a $7-$ valent pneumococcal conjugate vaccine and a 23-valent pneumococcal polysaccharide vaccine booster. Clin Vaccin Immunol: CVI 2010;17:1970-6.

[21] Ortqvist A, Henckaerts I, Hedlund J, Poolman J. Non-response to specific serotypes likely cause for failure to 23 -valent pneumococcal polysaccharide vaccine in the elderly. Vaccine 2007:25:2445-50.

[22] Musher DM, Watson DA, Baughn RE. Genetic control of the immunologic response to pneumococcal capsular polysaccharides. Vaccine 2000;19:623-7.

[23] McMahon BJ, Parkinson AJ, Bulkow L, Davidson M, Wainwright K, Wolfe P, et al. Immunogenicity of the 23-valent pneumococcal polysaccharide vaccine in Alaska Native chronic alcoholics compared with nonalcoholic Native and non-Native controls. Am J Med 1993;95:589-94. 
[24] Quinones-Parra S, Grant E, Loh L, Nguyen TH, Campbell KA, Tong SY, et al. Preexisting CD8+ T-cell immunity to the H7N9 influenza A virus varies across ethnicities. Proc Natl Acad Sci USA 2014;111:1049-54

[25] Paris K, Sorensen RU. Assessment and clinical interpretation of polysaccharide antibody responses. Ann Allergy, Asthma Immunol: Off Publ Am Coll Allergy, Asthma, Immunol 2007;99:462-4.

[26] Ameratunga R, Woon ST, Gillis D, Koopmans W, Steele R. New diagnostic criteria for common variable immune deficiency (CVID), which may assist with decisions to treat with intravenous or subcutaneous immunoglobulin. Clin Exp Immunol 2013;174:203-11.

[27] Bonilla FA, Bernstein IL, Khan DA, Ballas ZK, Chinen J, Frank MM, et al. Practice parameter for the diagnosis and management of primary immunodeficiency. Ann Allergy, Asthma Immunol: Off Publ Am Coll Allergy, Asthma, Immuno 2005;94:S1-S63.

[28] Sorensen RU, Leiva LE, Javier 3rd FC, Sacerdote DM, Bradford N, Butler B, et al. Influence of age on the response to Streptococcus pneumoniae vaccine in patients with recurrent infections and normal immunoglobulin concentrations. J Allergy Clin Immunol 1998;102:215-21.

[29] Rubins JB, Alter M, Loch J, Janoff EN. Determination of antibody responses of elderly adults to all 23 capsular polysaccharides after pneumococcal vaccination. Infect Immun 1999;67:5979-84.

[30] Romero-Steiner S, Musher DM, Cetron MS, Pais LB, Groover JE, Fiore AE, et al. Reduction in functional antibody activity against Streptococcus pneumoniae in vaccinated elderly individuals highly correlates with decreased IgG antibody avidity. Clin Infect Dis: Off Publ Infect Dis Soc Am 1999;29:281-8.

[31] Musher DM, Groover JE, Graviss EA, Baughn RE. The lack of association between aging and postvaccination levels of $\operatorname{IgG}$ antibody to capsular polysaccharides of Streptococcus pneumoniae. Clin Infect Dis: Off Publ Infect Dis Soc Am 1996;22:165-7.

[32] ATAGI. Updated recommendations for revaccination of adults with 23-valent pneumococcal polysaccharide vaccine (23vPPV), Pneumovax 23. 2011 